\title{
Application of Selection Method of Similar Products with Functional Difference in Tourism Route Design*
}

\author{
Ling Da \\ Institute of Southwest Minority Research \\ Southwest Minzu University \\ Chengdu, China 610041 \\ School of Economics \\ Guizhou University \\ Guiyang, China 550025
}

\begin{abstract}
The selection and combination of different scenic spots in the design of tourist routes play a decisive role in the realization of the economic benefits of the route. Based on the similarity theory, the article analyzes the possibility of choosing different route combination elements from the perspective of cost and profit in the design of tourism routes. This article studies how to effectively select the more effective attractions and project elements in the process of tourism route optimization and combination. The practical steps of the method are detailed through an example, which verifies the convenience and reliability of the theoretical method in the design of actual tourist routes.
\end{abstract}

Keywords-economic benefits; similar products; differences; cost profit margin; tourism routes

\section{INTRODUCTION}

Tourism route is an important part of tourism products. It is actually a reflection of the travel system on a linear trajectory, an entity that organically combines various individual tourism products together. [1]

Many scholars have studied the design of tourism routes from the perspective of tourists. From the spatial scale, Bao Jigang and Chu Yifang divided the tourism routes into two categories: large-scale tourism routes and small- and mediumscale tourism routes. Chen Qingguang and Zhou Maoquan constructed the viewpoint of a tourist route network based on the development of individual attractions. Liu Zhenli and Wang Bing put forward the five principles of tourism route design. In particular, the route design theory proposed by Chu Yifang is a leap from the qualitative to quantitative development of tourism route design methods. $\mathrm{He}$ systematically expounded the four main factors affecting the design of tourist routes, divided the design of tourist routes into four steps, and drew the operation curve diagram. [2] From the perspective of behavioral geography, Zhou Shangyi studied the differences in the choice of tourism routes for different groups, and proposed the design concept and evaluation method of

*Fund: Supported by the National Social Science Foundation of China (11XMZ047): Guizhou Agricultural and Forestry Economic Management Domestic First-Class Discipline Construction Project of Guizhou University in 2017 (GNYL [2017] 002). tourism routes. [3] These excellent theories have played a great guiding role in the development of tourism products, and have made significant contributions to the development of regional tourism economy. However, from the perspective of the research methods of tourism routes, there is almost no quantitative research through scientific methods, just some qualitative research. At present, the interdisciplinary nature of tourism design is relatively obvious. Wu Kai has proposed that quantitative analysis can be obtained by using operations research to analyze tourism routes. [4] Li Xuejuan proposed the use of Hopfield neural network algorithm and optimization model to realize the selection of the best travel route. [5] Zou Shilin improved the shortest path algorithm in GIS. He analyzed the shortest path relationship between various attractions in the tourist area according to $\mathrm{VC}++$, and obtained reasonable tourist routes in the tourist area. [6] Wang Ning proposed a new comprehensive evaluation method and route selection method based on fuzzy mathematics, which made the process of judging and selecting the tourist scene more objective and scientific. [7] Therefore, the current tourism route design mainly considers the market analysis of tourism routes, the components of the routes, and the status of the enterprise from a macro and media perspective, and often ignores the characteristics of internal factors of route products. This article quotes the relevant ideas of similarity theory, and studies the product functional difference selection of tourism routes from the perspective of product characteristics analysis, and provides a simple and effective quantitative selection idea for tourism route design.

\section{SElection Method}

\section{A. Theoretical Basis}

1) Similarity tourism products: Tourists' expectations for tourist routes are to meet their consumption needs to the greatest extent, with the least cost and the most convenient schedule. For travel agencies, on the premise of meeting the needs of tourists, they hope to reduce costs, improve efficiency, and adjust their routes in a timely manner in the face of emergencies. 
The tourist route composed of many elements can be regarded as a system to a certain extent. When there are common characteristics between systems, if there are differences in feature values, the corresponding common characteristics are called "similar characteristics". When there are similar characteristics between systems, it is considered that there is similarity between systems. [8] Function is the core and essence of the product and functional design is also the most important part in the design of tourism products. When the structures or functions of products are similar, these products are similar products [8]. A tourism product is a special product that combines a variety of factors. It is a comprehensive product that can meet the six basic needs of tourists: eating, living, traveling, traveling, shopping, and entertainment. According to the content of modern marketing on the division of product composition, the composition of tourism products includes the core part, form part and extension part. Among them, the core part of tourism products is tourism attractions and tourism services. The form of tourism products is the carrier, quality, characteristics, style, reputation, and combination of tourism products, and the extension of tourism products is the sum of various additional benefits obtained by tourists when they buy tourism products. [9] According to this designation, tourism products with similar structures and functions at the core can be called similar tourism products. For example, tourist routes on the same theme, hotels with the same star rating, and so on. The characteristics of similar products have similarities and differences. Similarity tourism products are more similar in the core part of the product, but also in the form part and the additional part. For example, the brand recognition, target market, sales concept, etc. of the same star hotel. Through the identification of similarity and difference characteristics, the optimal design of tourism products can be realized. Therefore, using similar technologies for product design is very helpful for enterprises to design tourism products with good economic benefits.

Cost-profit ratio: The economic benefits of a product are mainly determined by the profit from product sales and production costs. In investment economics, the formula for calculating the profit rate of product costs is [10]:

\section{Cost-profit ratio $=$ total sales profit/total costs $* 100 \%$}

This formula is an earning standard obtained at a certain cost under ideal market conditions and without considering other factors that affect benefits and costs. The cost-profit ratio is directly proportional to the total sales profit and inversely proportional to the total input cost. A tourist route is made up of many factors, and each additional factor will increase the cost of the route. The core part of a tourist route is the basic element that determines the nature of the route and is essential for route design. But the form and extension of the line (including new ones) are the factors that determine the characteristics and style of the product. They are individual and different, and they can be chosen to use. For example, Huangguoshu Pubu, Loong palace, and Tianxing Bridge are essential in establishing Guizhou's classic "Huang-TianDragon" tourist route. The Tianlong, Buyi Style Village and others in the later development are optional. As a tourist route, due to the definition of the quality of tourist products and the tourist's suitable tourism cycle, it is not that the more the function of tourist routes (attraction items), the better. Because choosing different functions will result in different costs and profits for the product. Therefore, when designing a product, one can choose a function with better economic benefits for the product by comparing the cost profit margin of these functions. [11] Also, some features have some differences in characteristics. These differences will bring different costs and profits to the product. One can also compare these different cost-benefit ratios of products due to differences in functional characteristics, so as to choose the functional characteristics with the best economic benefits.

\section{B. Selection Method of Product Function}

The functions of the product include the basic functions of the product and the extended functions of the product. The basic function refers to the function that the tourism product should provide to the customer. In the tourism product, it mainly refers to the core components of the product, such as the elements that must be provided to complete the tourism activities such as food, accommodation and travel during the tourism. In the design of tourist routes, more can be understood as the core attractions and content of a tourist route. These functions are required by the product, but are not included in the selection of functions. Product extensions are additional features provided to make it easier for customers to use the product. In tourism products, it mainly refers to the form part and core part of the product, such as some auxiliary attractions and gift items in the design of tourist routes. They play a rich and fulfilling role in the line and can be chosen to use. If in the designed tourist route, there are $\mathrm{m}$ extended functions (ancillary attractions) for selection, it is $\left(F_{1}, \cdots, F_{j}, \cdots\right.$, $\mathrm{F}_{\mathrm{m}}$ ). For any of these functions (adding attractions) $\mathrm{F}_{\mathrm{j}}$, the cost of the designed product without $\mathrm{F}_{\mathrm{j}}$ is $\mathrm{C}_{\mathrm{sj}}$ and the sales price on the market is $\mathrm{P}_{\mathrm{sj}}$. If the function $\mathrm{F}_{\mathrm{j}}$ is added, the cost of the tourist route increases to $\mathrm{C}_{\mathrm{aj}}$. However, since increasing $\mathrm{F}_{\mathrm{j}}$ not only increases the tourist function of the line, but also increases the market popularity of the entire line product, the sales price of the tourist line in the market will increase to $\mathrm{P}_{\text {aj. }}$. Then the cost $\mathrm{C}_{\mathrm{j}}$ of $\mathrm{F}_{\mathrm{j}}$ and the possible increased profit $\mathrm{P} j$ of the product are:

$$
\begin{aligned}
& \mathrm{C}_{\mathrm{j}}=\mathrm{C}_{\mathrm{aj}}-\mathrm{C}_{\mathrm{sj}} \\
& \mathrm{P}_{\mathrm{j}}=\mathrm{P}_{\mathrm{aj}}-\mathrm{P}_{\mathrm{sj}}
\end{aligned}
$$

Make $\mathrm{E} \mathrm{j}$ be the cost-profit ratio of this function, according to (1),

$$
\mathrm{E}_{\mathrm{j}}=\mathrm{P}_{\mathrm{j}} / \mathrm{C}_{\mathrm{j}}
$$

By calculating all the optional expansion functions in turn, the cost profit rate of each function can be obtained. The set is $\left(\mathrm{E}_{1}, \cdots, \mathrm{E}_{\mathrm{j}}, \cdots, \mathrm{E}_{\mathrm{m}}\right)$. Then letting $\mathrm{B}_{1}=\mathrm{m}_{\mathrm{ax}}\left(\mathrm{E}_{1}, \cdots, \mathrm{E}_{\mathrm{j}}, \cdots, \mathrm{E}_{\mathrm{m}}\right)$, and $\mathrm{B} 2$ be the second largest value in the set, and obtain the sequence $\left(\mathrm{B}_{1}, \cdots, \mathrm{B}_{\mathrm{j}}, \cdots, \mathrm{B}_{\mathrm{m}}\right)$. It is easy to know that $\mathrm{B}_{1} \geq \mathrm{B}_{2} \geq \cdots \geq$ $\mathrm{B}$, which means that the function represented by $\mathrm{B} 1$ is the function with the best economic benefits (elements), followed by $\mathrm{B}_{2}$, and so on; $\mathrm{B}_{\mathrm{m}}$ is the function with the worst economic benefits (elements). If a function is selected for a product, then some of the functions represented by the previous elements in this sequence should be adopted sequentially from $\mathrm{B}_{1}$. In the 
the line elements. According to formulas (2) and (3), it can calculate or improve the cost required for each optional element and the profit it can bring to the line sales, and then use formula (4) to calculate the cost profit margin of adding or improving each function. If the cost control needs to be considered in the design, it can be selected according to formula (5).

\section{APPLICATION EXAMPLES OF SELECTION WITH FUNCTIONAL DIFFERENCES OF SIMILAR TOURIST PRODUCTS IN THE TOURIST ROUTE DESIGN}

Taking the design of rural tourism routes in Bishan County as an example, the application of this design method in the design of tourism routes is explained. According to the basic situation, the main tourist attractions originally included in Bishan's "rural ecotourism" themed tourist routes were from the Bishan City then South Bishan High-efficiency Ecological Sightseeing Agriculture Area then Jinyunhoushan Ecological Tourism Area then Qinglong Lake Tourism Area then Jintang Lake Tourism Area and finally to the Dingjia Flower Nursery Ecological Tourism Area. [12] The original cost of the line was 250 yuan, and the market price was 400 yuan. In order to effectively promote the development of surrounding scenic spots and enrich the content of routes to meet the needs of different tourism consumers, the original routes need to be optimized and reorganized. Considering the competitiveness of the Bishan Ecological Rural Tourism Route in the country, the cost of the route optimization can only increase by up to 100 yuan. Combined with market preference surveys, as well as the combined status and operating costs of various tourism resource points, it has obtained several additional tourist attractions that optimize routes and highlight product features.

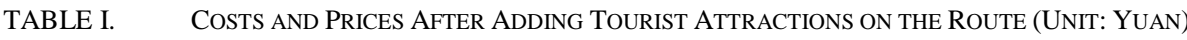

\begin{tabular}{clcc}
\hline $\begin{array}{c}\text { Function } \\
\text { Number }\end{array}$ & \multicolumn{1}{c}{$\begin{array}{c}\text { Names } \\
\text { of Scenic Spots }\end{array}$} & Cost of Route & Market Price \\
\hline $\mathrm{F}_{1}$ & Hequn Boutique Pear Garden & 300 & 470 \\
$\mathrm{~F}_{2}$ & Maolai Mountain Tourist Area & 270 & 420 \\
$\mathrm{~F}_{3}$ & Laifeng Food Court & 285 & 440 \\
$\mathrm{~F}_{4}$ & Hanlin Mountain Villa & 320 & 485 \\
\hline
\end{tabular}

Using (2), (3), and (4), the costs, increased profits, and costmargin ratios required to increase each tourism item were calculated. See "Table II".

TABLE II. The Cost, Profit AND COST-Profit RATIO of EACH FunCtion AdDED OR IMPROVED

\begin{tabular}{cccc}
\hline Function Number & Cost/Yuan & Profit/Yuan & Cost-Profit Ratio/(\%) \\
\hline$F_{1}$ & 50 & 70 & 1.4 \\
$F_{2}$ & 20 & 20 & 1 \\
$F_{3}$ & 35 & 40 & 1.14 \\
$F_{4}$ & 70 & 85 & 1.21 \\
\hline
\end{tabular}


[8] Zhou Meili. Science of Similarity [M]. Beijing: Science Press, 2004. (in Chinese)

From the above table, $E_{1}>E_{4}>E_{3}>E_{2}$, it can be seen that $E_{1}$ is the most effective tourist spot and $\mathrm{E}_{2}$ is the least effective tourist spot. Since $C_{1}+C_{2}+C_{3}+C_{4}=175>100$, it can't add all the project points, only can choose. According to formula (5), $\mathrm{C}_{1}+\mathrm{C}_{3}=85<100$, and $\mathrm{C}_{1}+\mathrm{C}_{3}+\mathrm{C}_{4}=155>100$, so if the cost constraint is met, the optional additional tourist attractions are $F_{1}$ and $F_{3}$, namely Hequn Boutique Pear Garden and Laifeng Food Street.

\section{CONCLUSION}

The selection of traditional route elements is often more based on the survey of tourist preferences, geographical behavior differences, and feature analysis of attractions, etc., and uses some technical theoretical methods and models to analyze the relationship between route constituent elements (especially different attractions). It must be emphasized that the combination of tourism products is different from other products. It is not only to control the increase of tourism project points from the perspective of profit control, but also from the perspective of tourism demand, the characteristics of the macro-elements of the route and the combined characteristics of the route, effectively realizing the scientific and reasonable design of tourist routes. Due to the great subjectivity and individual differences in the choice and preference of routes, the study of tourist preferences and behaviors must be the starting point and destination of route design. However, as far as tourism enterprises are concerned, all production processes must consider returns, and the pursuit of profit is the core of the enterprise. This method effectively realizes the quantification of the combination cost of the line element selection of the enterprise. Using the control method of cost profit rate, the enterprise can obtain the maximum benefit with a small profit. In the course of tourism route design, cost control was effectively realized. In practice, it can be used as an important means of matching and screening of the constituent elements of the route, effectively making up for the randomness and subjectivity of the choice of the usual route elements.

\section{REFERENCES}

[1] Jiang Sangeng. Tourism Planning [M]. Beijing: Capital University of Economics \& Business Press, 2002 (in Chinese)

[2] An Shiwei, Shan Chengzong. Research on the "Trinity" Methodology of Tourism Route Design [J]. Journal of Henan Institute of Education (Natural Science Edition). 2005, 09: 45-48. (in Chinese)

[3] Zhou Shangyi, Li Shufang, Zhang Jiangxue. Behavioral Geography and the Design of Urban Tourism Routes: Taking the Design of Suzhou One-day Tour Routes as an Example [J]. Tourism Tribune, 2002, 05: 66-70. (in Chinese)

[4] Wu Kai. Operational research problem in the design and optimization of tourism routes [J]. Tourism Science, 2004, 01: 34-37. (in Chinese)

[5] Li Xuejuan, Cui Shangsen, Zhang Ke. Traffic and Computer [J] .2006, 05: 103-106. (in Chinese)

[6] Zou Shilin, Ruan Jian. Application of Shortest Path Algorithm in Tourism Route Planning -Taking Lushan as an Example [J]. Science of Surveying and Mapping, 2008, 09: 190-193 (in Chinese)

[7] Wang Ning. Comprehensive Evaluation of Tourist Attractions in Scenic Spots and Selection of Optimal Tourist Routes [J]. Journal of Ningde Normal University (Natural Science), 2003, 05: 148-152. (in Chinese)
[9] Ma Yong, Bi Doudou. Tourism Marketing [M]. Shantou University Press, 2003.

[10] Deng Xiangrong. Investment Economics [M]. Tianjin: Tianjin University Press, 2002. (in Chinese)

[11] Yao Zhonghua. Analysis of Enterprise Core Competence and Customer Value [J]. On Economic Problems, 2001, 12: 32-33. (in Chinese)

[12] Chongqing Normal University. Tourism Development Plan of Bishan County (2008-2020) [Z]. 2008, 10. (in Chinese) 